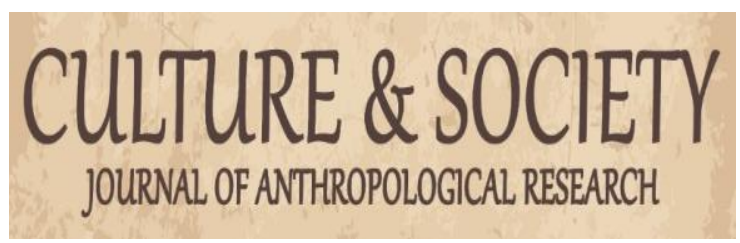

Culture \& Society: Journal of Anthropological Research

VOL. 2 NO. 4 JUNI 2021

http://culture.ppj.unp.ac.id

Email: culture@ppj.unp.ac.id

ISSN: 2686-343X (E-ISSN) 2686-3421 (P-ISSN)

DOI: https://doi.org/10.24036/csjar.v2i4.76

\title{
Makna Tari Gandai Bagi Masyarakat Desa Tunggang
}

\author{
Yulianti Mayangsari Putri Utami ${ }^{1}$, Erda Fitriani ${ }^{2}$ \\ ${ }^{1,2}$ Universitas Negeri Padang \\ Email: yuliantimayangsaripu.@gmail.com, erdafitriani@fis.unp.ac.id
}

\begin{abstract}
Abstrak
Artikel ini bertujuan untuk menjelaskan makna simbol tari gandai bagi masyarakat Desa Tunggang, Kecamatan Pondok Suguh, Kabupaten Mukomuko. Penelitian ini menjadi menarik karena tari gandai masih dilaksanakan oleh masyarakat desa ini ditengah maraknya masuk musik atau tari yang bernuasa modern terutama yang dilaksanakan pada upacara perkawinan. Selain daripada itu penelitian ini berbeda dari penelitian sebelumnya yang sudah ada, karena berupaya menggali secara holistik makna tari gandai makna tarian gandai bagi masyarakat. Penelitian ini dilakukan dengan menggunakan pendekatan kualitatif dengan jenis penelitian etnografi. Teknik pemilihan informan dengan menggunakan teknik snowball sampling, dengan jumlah informan sebanyak 20 orang. Pengumpulan data dilakukan dengan cara observasi, wawancara mendalam, studi dokumen, dan teknik Analisis data yang digunakan dalam penelitian ini yaitu model analisis etnografi yang diperkenalkan oleh Clifford Geertz.Teori Interpretivisme Simbolik ini memusatkan pada kebudayaan didasarkan penafsiran dan melalui penafsiran tersebut manusia mengontrol sikap dan perilakunya, menjalankan suatu kebiasaan dan keyakinan yang didapat oleh individu dan masyarakat sebagai warisan yang diperoleh dan harus dijalankan. Berdasarkan pada hasil penelitian, diperoleh kesimpulan, terdapat makna simbol dari tari gandai yang bermakna nilai moral dan kebersamaan, simbol dari berbalas pantun yang mengandung makna kehidupan percintaan mempelai, sindiran kepada penonton, sindirian kepada keluarga jauh yang sudah lama tidak pulang, kemudian simbol gerakan yang memiliki makna kehidupan sehari-hari, mulai dari gerakan hewan, cara bercocok tanam dan juga bermakna kegigihan masyarakat dalam kehidupan dan musik sebagai komponen pelengkap yang harus ada dalam gandai dan sebagai pengantar makna dari tarian gandai dengan menyesuaikan tema dari tari gandai.
\end{abstract}

Kata kunci: Makna, Simbol, Tari Gandai, Interpretivisme Simbolik, Tradisi

\section{Abstract}

This article aims to explain the meaning of the symbol of the clever dance of the people of Tunggang village, Pondok Suguh district, Mukomuko regency, this research is interesting because the clever dance is carried out by the village community in the midst of the inclusion of the modern music or dance, especially those carried out at wedding ceremonies, in addition, this study is different from previous studies that have been there, because is seeks to holistically the meaning of the clever dance, the meaning of the clever dance for society. This research was conducted using qualitative approach with ethnographic research type. The technique of selecting informants using the snowball sampling technique, with the number of informants as many as 20 people. Data collection was carried out by means of observation, in-depth interviews, document study, and data analysis tecniques used in this study, namely the analysis of the ethnographic analysis model introduced by Clifford Geertz. This symbol interpretivism theory focuses on the culture of interpretation and throught this interpretation, humans control their attitudes and behavior, carry out habits and beliefs acquired by individuals and society as an inheritance that is obtained and must be carried out. Based on the results of the research, it is concluded that there is a symbolic meaning of the clever dance which states moral values and togetherness, symbols of reciprocating rhymes which contain the meaning of live from the statement of the bride and froom, satire to the audience, satire to distant family who has not been home for a long time, then haven't been home for a long time, then the symbol of movement which has the meaning of everyday life, starting from animal movement, farming methods and also the persistence of society in life and music as complementary components that must be present in gandai and as an introduction to the meaning of the clever dance by adjusting th theme from the gandai dance.

Keywords: Meaning, Symbol, Gandai Dance, Symbolic Interpretivism, Tradition

\begin{tabular}{|c|c|c|}
\hline Received: May 2, 2021 & Revised: June 2, 2021 & Published: June 4, 2021 \\
\hline & (c) (i) ( ) \\
\hline
\end{tabular}

Culture \& Society: Journal of Anthropological Research Vol. 2, No. 4, Th. 2021

2686-343X (E-ISSN) 2686-3421 (P-ISSN)

Copyright (C) 2021, by Author. 


\section{Pendahuluan}

Kesenian adalah hasil dari ide-ide dan kebiasaan manusia yang ada dari dalam diri manusia dan dinyatakan melalui nilai-nilai keindahan dan keluhuran lewat berbagai cabang seni (Danis, 2017). Salah satu kesenian tari yang masih ada dan berkembang hingga saat ini yaitu tari gandai, tari gandai berasal dari kabupaten Mukomuko. Tari gandai ini berasal dari kata gando memiliki arti sama dengan kata ganda, maksud dari kata gando yaitu tarian gandai tersebut ditarikan secara berpasangan walau mereka menari dengan jumlah lebih dari sepasang mereka akan tetap menari secara berpasangan karena pada mulanya tari gandai itu dipercaya oleh masyarakat Mukomuko berasal dari kisah Malin Deman dan Puti Bungsu yang menjalin asmara sampai ke jenjang pernikahan karena pada saat itu Puti Bungsu memiliki 6 saudara perempuan yang sangat pandai menari dan memeriahkan acara pernikahan mereka (Refisrul, 2018).

Tujuan tari gandai sendiri, awal digunakan yaitu sebagai hiburan bagi Malin Deman yang kehilangan istrinya Puti Bungsu, pada perkembangannya sebagai penghibur saat pelaksanaan bimbang (pesta perkawinan) dan menghibur para kerabat dan tetangga saat sedang mempersiapkan pernikahan pada hari berikutnya. Ketika tidak adanya pertunjukan tari gandai masyarakat akan merasa kegiatan tersebut tidak berarti. Pelaksanaan oleh pihak penyelenggara gandai pada saat upacara perkawinan (bimbang) pada dasarnya yaitu orang yang punya acara, yang lumrah dipanggil dengan sepangkalan. Sepangkalan itu yang mengundang sanggar gandai serta menyiapkan semua keperluan supaya pementasan tari gandai berlangsung dengan lancar (Refisrul, 2018) ketika itulah tari gandai berkembang di lingkungan masyarakat dan selalu ditampilkan pada acara-acara, salah satunya yaitu pada upacara perkawinan di lingkungan masyarakat tersebut, daerah yang masih selalu menampilkan tari gandai pada upacara perkawinan salah satunya yaitu Desa Tunggang.

Peneliti akan menfokuskan pada makna tarian gandai dalam upacara perkawinan masyarakat Tunggang, makna yang dimaksud oleh peneliti yaitu arti penting tarian gandai bagi masyarakat, sehingga tarian ini masih menjadi sebuah pertunjukan yang penting bagi masyarakat di Desa Tunggang untuk selalu dipertunjukan pada upacara perkawinan. Alasan memilih lokasi penelitian di Desa Tunggang karena desa tersebut merupakan desa yang masih selalu mengadakan dan mengikutsertakan kesenian gandai pada setiap upacara perkawinan.

Berdasarkan hasil penelitian yang dilakukan oleh Marfinetri Elyadi, mengenai perkembangan Tari gandai pada Masyarakat Mukomuko Provinsi Bengkulu. Hasilnya yaitu pada awalnya fungsi kesenian tari gandai tersebut dimaksudkan untuk menjadi penyemangat atau menghibur orang-orang yang sedang bekerja, kemudian berkembang menjadi media pembelajaran dan memperkuat solidaritas sosial (pemersatu) di tengah masyarakat. Melalui pantun disela-sela gandai tersebut, bisa disampaikan nilai-nilai budaya atau norma sosial kepada penontonnya yang terutama generasi muda. Perubahan-perubahan pada dasarnya merupakan penyesuaian atau adaptasi pelaksanaan kesenian gandai dalam menyikapi perkembangan zaman yang sesungguhnya tidak menghilang substansi tari gandai sebagai kesenian tradisional.

Sedangkan penelitian yang dilakukan oleh Refisrul mengenai Eksistensi Tari Gandai pada Masyarakat Mukomuko. Hasilnya yaitu tari gandai pada dasarnya adalah kekayaan adat istiadat orang Mukomuko yang masih tetap dilestarikan hingga saat ini, terutama pada kegiatan upacara perkawinan (bimbang), nyanyian syair dari pantun dan musik, dimainkan oleh para perempuan dengan berpasang-pasangan melalui penggunaan alat musik yaitu sunai dan redap, tari gandai pada hakikatnya selalu dikembangkan sebagai fungsi sosial dan nilai moral, serta kearifan pada penerapanya (Refisrul, 2018)

Seluruh penelitian yang sudah ada berkaitan dengan tarian gandai, mulai dari eksistensi, perkembangan dan perubahan tarian gandai.Kesamaannya dengan penelitian yang dilakukan yaitu terkait subjeknya yaitu meneliti tarian gandai, tetapi hal yang kemudian luput dari penelitianpenelitian sebelumnya yakni belum secara komprehensif menjelaskan arti penting tarian gandai itu sendiri diadakan pada upacara perkawinan sehingga cenderung tarian gandai ini sekedar menjadi 
hiburan pada sebuah upacara perkawinan dan hanya diadakan jika pemilik acara ingin menyertakan gandai pada upacara perkawinan.

Guna menjelaskan makna tradisi tari gandai pada upacara perkawinan, peneliti menggunakan Teori Interpretivisme Simbolik oleh Clifford Geertz, kebudayaan itu adalah suatu pola simbol makna yang dijalankan dengan cara sejarah yang tergambar dalam sebuah simbolsimbol, suatu bentuk konsep yang diambil dan dijelaskan ke dalam bentuk simbolis dengan itu manusia berkomunikasi, melestarikan dan mengembangkan pengetahuan mereka terkait kehidupan dan perilaku-perilaku kehidupan (Saifudin 2006). Maksudnya untuk menjelaskan sebuah budaya yang terdapat dalam elemen lingkungan masyarakat, seseorang diharuskan untuk memahami simbol-simbol yang terkandung dalam masyarakat.

Budaya dipandang sebagai sebuah sistem yang berkaitan dengan unsur-unsur yang dapat dijelaskan, maksudnya kebudayaan itu adalah sebuah penjelasan, dan sesuatu didalamnya dijabarkan secara detail dan akurat (Geertz, 2016). Geertz menjelaskan budaya sebagai: (1) sebuah sistem ketetapan dari makna dan simbol-simbol itu kalangan masyarakat menjelaskan, mempresentasikan pendapat dan memberikan sebuah penilaian: (2) suatu bentuk makna-makna ditransmisikan dengan cara sejarah yang berisi di dalam bentuk-bentuk simbol itu masyarakat berinteraksi, memperjelas dan mengembangkan wawasan mereka mengenai berperilaku untuk kehidupan mereka: (3) sebuah sikap simbolik untuk kontrol perilaku, sumber-sumber penting dan jelas dari sebuah informasi: dan (4) pada dasarnya budaya yaitu suatu simbol, oleh sebab itu proses kebudayaan perlu dicermati, diartikan, dan diinternalisasikan dalam kehidupan (Saiffudin, 2006)

Berdasarkan penjelasan di atas penelitian ini dianalisis dan dikaji melalui teori interpretivisme simbolik oleh Clifford Geertz yang dapat menjelaskan bahwa makna tradisi tari gandai pada upacara perkawinan merupakan gambaran dari kegiatan anggota masyarakat yang dilakukan pada upacara perkawinan. Pada kegiatan tersebut diperoleh sebuah tindakan yang bermakna simbol, sehingga dari simbol tersebut dapat dipahami arti dari makna ativitas gandai pada masyarakat itu. Simbol sendiri adalah objek, kejadian, bunyi, bicara, atau bentuk-bentuk tertulis yang diberi makna oleh manusia (Yolanda, Amri, \& Fitriani, 2020).

\section{Metode penelitian}

Penelitian ini termasuk ke dalam pendekatan kualitatif, penelitian kualitatif bertujuan untuk memaham peristiwa terkait apa yang terjadi pada subjek penelitian dengan cara penjelasan dengan bentuk kata-kata dan bahasa pada suatu penjelasan istimewa yang alami dengan menggunakan berbagai model ilmiah (Moleong, 2012), dengan pendekatan ini peneliti dapat memperoleh informasi secara langsung dari pihak yang terkait dalam rangka memahami makna tradisi tari gandai pada upacara perkawinan masyarakat Desa Tunggang. Pendekatan kualitatif bertujuan untuk mendeskripsikan sebuah fenomena sosial yang diteliti, namun yang terpenting adalah menjelaskan dan mengaktualisasikan makna dari peristiwa yang ada, (Moleong, 2012). Pendekatan ini dipilih dengan pertimbangan, dapat membuka peluang untuk mengungkap pengertian atau pemahaman yang tepat mengenai suatu gejala atau tingkah laku sosial dan budaya setempat.

Dilihat dari tipe penelitian ini adalah penelitian etnografi. Etnografi merupakan penelitian mengenai suatu kebudayaan dari suatu etnik, seperti yang dikemukakan oleh Malinowski, terkait studi etnografi digunakan untuk memahami pemikiran masyarakat setempat, interaksinya dengan kehidupan sehingga mendapatkan pandangannya mengenai dunia (Spradley, 1997), dengan menggunakan penjabaran interpretatif bertujuan untuk mendapatkan sebuah penjelasan yang lebih akurat tentang gejala sosial tertentu.

Penelitian ini berlokasi di Desa Tunggang, Kecamatan Pondok Suguh, Kabupaten Mukomuko dengan alasan yaitu, Desa Tunggang adalah salah satu desa di Kabupaten Mukomuko yang masih selalu mengadakan pertunjukan tari gandai pada upacara perkawinan, tari gandai pada desa tersebut masih dianggap penting sebagai kebudayaan turun temurun masih terus 
dilestarikan meski pengaruh modernisasi semakin besar, tetapi masyarakat Desa Tunggang tetap menjalankan tradisi warisan leluhur mereka agar dapat diteruskan oleh generasi selanjutnya.

Teknik pemilihan informan pada penelitian ini dilakukan dengan teknik snowball sampling, ini adalah suatu metode untuk mengindetifikasi, memilah informan dalam suatu bentuk hubungan yang berkelanjutan. Pada penggunaannya, teknik snowball sampling adalah didasarkan pada sebuah bola salju, dimulai melalui tahapan bola salju kecil kemudian membesar secara perlahan karena ada tambahan salju ketika dilemparkan pada dataran salju. Ini diawali dengan beberapa individu atau masalah, kemudian diperluas melalui hubungan-hubungan dengan informan. informan sebagai sumber yang mewakili populasi (Nurdiani, 2014) informan pada penelitian ini berjumlah 20 orang diantaranya yaitu: 8 orang penari sebagai informan pendukung ,6 orang penonton sebagai informan pendukung, 3 orang pemusik sebagai informan pendukung dan 2 orang penyair , sebagai informan utama yaitu 1 orang tokoh adat/induk gandai sebagai informan kunci/utama.

Teknik pengambilan data yang digunakan oleh peneliti adalah observasi partisipasi, wawancara mendalam, dan studi dokumen. agar mendapatkan sebuah keabsahan dan kebenaran yang pasti terhadap data penelitian, maka peneliti harus melakukan triangulasi data, triagulasi dilakukan dengan menggunakan sumber dan metode. Analisis data yang digunakan dalam penelitian ini yaitu model analisis etnografi yang diperkenalkan oleh Clifford Geertz, dengan langkah-langkah, hermeneutik data, menginterpretasikan data, dan data dipresentasikan (Endraswara, 2012).

\section{Hasil dan Pembahasan}

\section{Makna Tradisi Tari Gandai Bagi Masyarakat Desa Tunggang, Kecamatan Pondok Suguh, Kabupaten Mukomuko.}

Tujuan dari penelitian ini untuk mengetahui simbol yang terdapat pada tarian gandai berkaitan dengan gerakannya, simbol dari kostum yang digunakan, simbol dari musik serta simbol dari penyampaian pantun, sehingga membantu peneliti memahami makna yang terdapat/terkandung pada tari gandai pada upacara perkawinan, sehingga masyarakat Desa Tunggang masih selalu menyertakan tari gandai pada upacara perkawinan.

Dari makna simbol tari gandai sendiri pada penelitian, peneliti mendapatkan informasi yang paling mendasar terkait makna tari gandai bagi masyarakat Desa Tunggang yaitu terdapat nilai moral, dan merupakan proses sosialisasi antara penari dan penonton, penyair dan penonton, gandai dinilai memiliki makna simbol sebagai pengingat kembali kisah masalalu dari leluhur masyarakat setempat. Gandai sebagai warisan budaya yang harus terus dikembangkan agar generasi berikutnya paham bahwa gandai adalah tradisi yang harus dilestarikan. Penjelasan mengenai makna tari gandai akan dipaparkan dibawah ini:

\section{Makna Simbol Tari Gandai Secara Emik}

\section{Makna Simbol Pada Pertunjukan Gandai}

Tarian gandai pada upacara perkawinan selalu dilakukan pada malam hari sebelum dilaksanakannya pesta perkawinan keesokan harinya mulai dari pukul 21.00 malam hingga menjelang subuh. Tarian gandai sebelum dilaksanakan terlebih dulu mempersiapkan alat-alat yang akan digunakan, ketika gandai mulai dilaksanakan masyarakat akan mulai berdatangan untuk menyaksikan pertunjukkan tersebut, mulai dari kalangan remaja hingga lansia ikut berpartisipasi menonton pertunjukkan gandai. Gandai tidak hanya ditarikan oleh penarinya saja, apabila gandai beradat ditampilkan, maka para ibu-ibu yang menonton akan ikut serta menari dan hal ini bermakna kebersamaan dan keikutsertaan para ibu-ibu tersebut akan memunculkan interaksi antara satu dengan yang lainnya. Kostum yang digunakan menyesuaikan pakaian adat daerah dengan selendang, umumnya dipakai oleh anak gandai/penari sehingga ibu-ibu dari kalangan penonton hanya menggunakan pakaian biasa, simbol dari selendang sendiri mengikuti tarian yang 
dimainkan oleh kerabat Puti Bungsu untuk menghibur Malin Deman yang kehilangan Puti Bungsu.

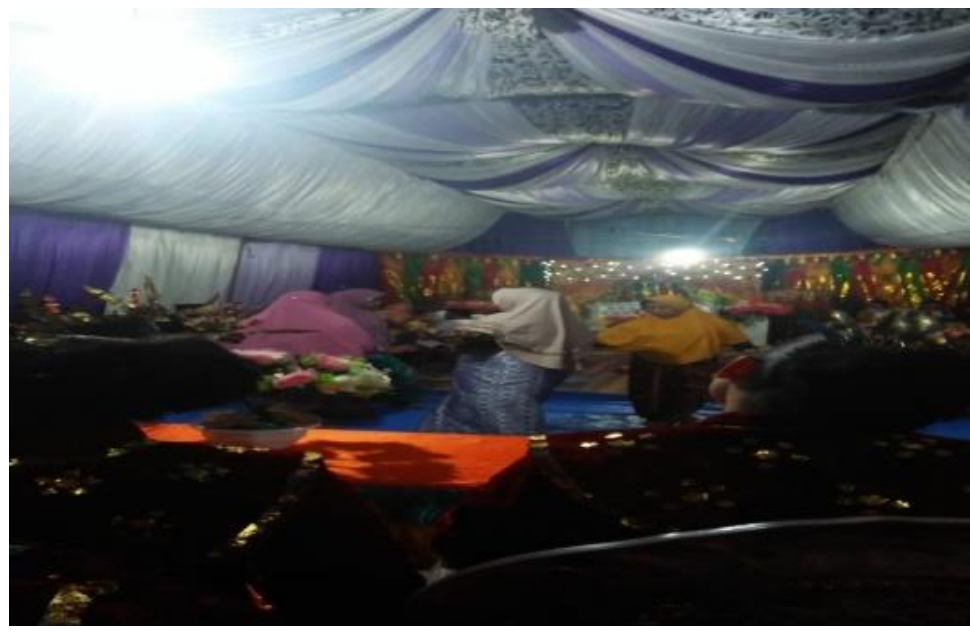

Gambar 1. Gandai Beradat

Ketika sebelumnya antar masyarakat jarang berkomunikasi, dengan diadakannya pertunjukan gandai keakraban antar masyarakat akan terjalin lebih harmonis sehingga terdapat makna pada simbol tarian gandai yaitu terdapat nilai moral terkandung didalamnya Nilai moral adalah sisi kebenaran yang senantiasa dijalankan oleh individu atau kelompok di dalam lingkungan sosialnya. Berkaitan dengan hal tersebut maka muncullah prinsip dan keyakinan tentang perilaku yang berhubungan dengan benar atau salah seperti kebiasaan yang dilakukan secara terus menerus oleh masyarakat Desa Tunggang sehingga menjadikan gandai sebagai sebuah tradisi budaya yang memiliki nilai untuk terus dilestarikan di lingkungan masyarakat tersebut. Karena dengan adanya gandai mereka akan melupakan sejenak aktivitas mereka yang membuat antar masyarakat jarang berkomunikasi menjadi akrab kembali. Hal ini dijabarkan berdasarkan hasil wawancara peneliti dengan informan terkait gandai di desa tunggang, di peroleh informasi yang disampaikan oleh $\mathrm{M}$ (50 tahun) yaitu:

"...gandai kok ngapo nyo selalu diadokan nyo ka ado pesan moral di dalam e apo ling gandai baradat pasti ado nilai kebersamaan yang hadir, sesamo keluargo wak kumpul, penting nian ado, kalau dak ado gandai ko, manu nyua ndak gaek-gaek ko datang, nyo kalau orgen palingan anak-anak mudo, kalau ado gandai ko kan segalonyo bisa hadir, jadi ado nilai kebersamaan di dalamnyo tu.

Bahasa Indonesia:

“...Gandai ini kenapa selalu diadakan karena ada nilai kebersamaan di dalamnya apalagi gandai beradat pasti ada nilai moralnya yang hadir, sesama keluarga kita kumpul. Penting sekali ada, kalau tidak ada gandai ini, tidak akan mau yang tua-tuanya datang, kalau orgen paling anak-anak muda, sementara kalau ada gandai semua bisa datang, jadi ada nilai kebersamaannya di dalamnya".

Dari apa yang disampaikan Bapak M, dapat disimpulkan alasan tarian gandai masih selalu tampil pada pesta perkawinan yaitu karena terdapat pesan moral dalam tarian gandai tersebut seperti gandai beradat, gandai beradat adalah gandai yang dilakukan dengan tradisi mengikutsertakan pengantin wanita untuk menari gandai dan menyertakan para sanak saudara dan para penonton untuk ikut menari jika ingin ikut serta. Sehingga gandai ini akan menambah daya tarik para penonton untuk menonton pertunjukan tersebut. Sehingga gandai juga dinilai akan mengumpulkan semua kalangan masyarakat setempat dan menjadi sebuah nilai kebersamaan. 


\title{
Makna simbol Berbalas Pantun pada Pertunjukan Gandai
}

Pantun adalah puisi lama yang digunakan pada saat acara-acara tertentu salah satunya yaitu menjadi komponen pada gandai, dalam penyampaiaannya terdapat simbol-simbol tertentu, seperti penyampaian pantun percintaan, pantun nasihat, pantun jenaka, dan pantun sindiran yang bermakna menceritakan kehidupan sehari-hari, baik dari segi percintaan antar mempelai maupun penonton, juga pantun sindiran yang ditunjukkan kepada para penonton yang belum menikah karena dengan pantun penyampaiaan pesan akan jelas dan menambah daya tarik masyarakat untuk ikut serta berpantun.

Hal ini dijabarkan berdasarkan hasil wawancara dengan saudari MS (27 tahun):

“...gandai ko memang dak habis dimakan zaman nyo ko banyak pertunjukan dalam nyo, ado ugang yang nari, ado pemain musik ado go yang tukang pantun, nyo kalau tukang pantun ko isinyo tentang kehidupan sehaghi wak ko. Kelak nyo berbalas jo kek penonton e, itulah yang buek ugang ko endak nnton gandai ado pulak pantun nyo ko buek gaming.

Bahasa Indonesia:

“...Gandai ini memang tidak habis dimakan zaman, banyak sekali pertunjukan di dalamnya, ada penari, ada pemain musik, ada juga yang menyampaikan pantun, kalau tukang pantun yang disampaikannya lebih ke kehidupan sehari-hari. Nanti penyair itu akan berbalas pantun dengan penonton, itulah yang buat orang mau menonton gandai karena ada pula pantun itu yang buat ramai".

Adapun syair pantun yang sering dibawakan yaitu:

\section{"lah lamung dak paing kahimbo \\ Semak bebuah indak badughi \\ Lah lamung dak jumpo \\ Apo keba sanak kini"}

Artinya:

\author{
Sudah lama tidak pergi kehutan \\ Semak berbuah tidak berduri \\ Sudah lama tidak bertemu \\ Apa kabar teman sekarang
}

Makna dari pantun tersebut berdasarkan wawancara dengan saudari MS (27 tahun) adalah sudah lama tidak pergi ke hutan sebagai sampiran, semak berbuah tidak berduri juga merupakan sampiran, sudah lama tidak bertemu, bermaksud seperti kerabat yang di rantau jarang pulang, dan menyempatkan pulang karena ada keluarga yang menikah sehingga pada pertunjukan gandai tersebut mereka dapat berkumpul dan saling bertanya kabar antara satu dengan yang lainnya. Dari penyampaian pantun di atas dapat disimpulkan bahwa dalam tarian gandai itu unsurnya lebih meceritakan tentang kehidupan sehari-hari, cara bergaul dengan sesama individu, syair pantun sangat besar pengaruhnya kepada penonton karena semakin menarik pantun yang disampikan maka akan semakin ramai yang ingin berbalas pantun.

Pantun ini di tampilkan dengan cara ditampilkan secara berirama mengikuti gerak tarian yang ditarikan oleh penari. Pantun yang disampaikan memiliki sebuah makna simbol dan nilai yang menyatakan sebuah ungkapan perasaan penari atau tukang pantun. Dengan penyampaian pantun tersebut akan memberikan pesan secara tersirat baik bagi penonton maupun para kalangan keluarga atau sanak saudara yang hadir dalam pertunjukan gandai sehingga akan mengingatkan kembali keluarga yang sudah lama tidak bertemu terhadap penting silaturahmi. 


\section{Makna Simbol Gerakan Pada Tarian Gandai}

Gerakan tari merupakan unsur utama dalam tarian yang dilakukan setiap individu penari maupun secara kelompok dan berpasangan. Tabel dibawah dapat dilihat jenis gerakan yang ada pada tari gandai.

Tabel 1. Gerakan Tari Gandai

\begin{tabular}{ll}
\hline No & Jenis Gerakan Pada Tarian Gandai \\
\hline 1 & Gerakan Tari Gandai Jagung \\
\hline 2 & Gerakan Tari Gandai Nenet \\
\hline 3 & Gerakan Tari Gandai Rantak Kudo \\
\hline 4 & Gerakan Tari Gandai Kuok Letok \\
\hline 5 & Gerakan Tari Gandai Beradat \\
\hline \multicolumn{2}{l}{ Sumber: wawancara informan MS (27tahun) }
\end{tabular}

Dengan mengikuti alunan musik penari akan leluasa memberikan gerakan dari anggota tubuh pada tempat dan waktu tertentu. Gerakan pada tarian gandai sendiri adalah tarian yang bermakna, karena memiliki simbol-simbol tertentu pada setiap jenis gerakannya sehingga dari simbol tersebut terdapat makna yang di dalamnya, seperti simbol pada tari jagung yang memiliki makna sebagai gambaran proses masyarakat dalam bercocok tanam, kemudian rantak kuda yang bermakna kegigihan dan kehidupan yang tanggung megikuti gerakan hewan seperti kuda yang pemberani, kemudian kuou letok mengikuti gaya burung kuou yang sedang kelaparan hal tersebut disampaikan dengan makna dan tujuan secara spesifik yang memiliki banyak pola gerakan dan terkandung makna-makna secara tersirat dan disampaikan melalui berbagai macam ragam gerak.

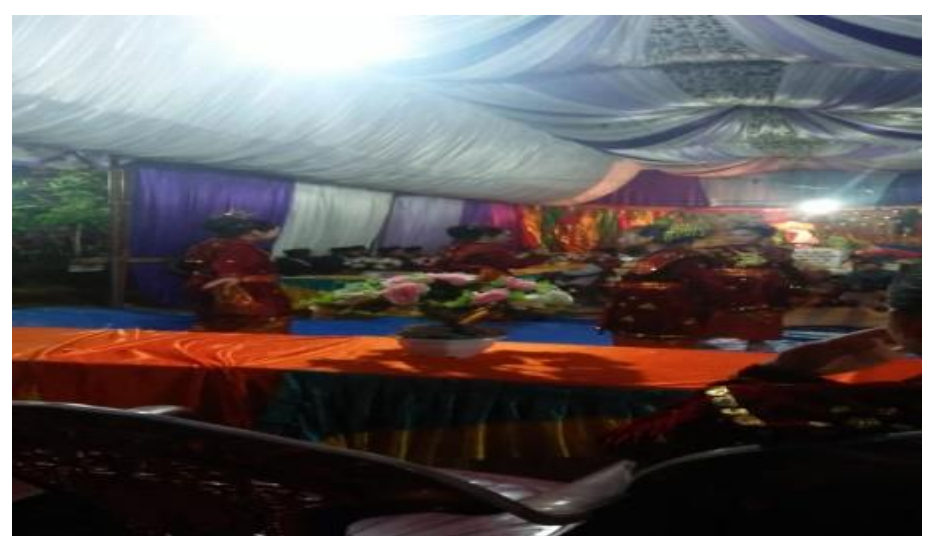

Gambar 2. Gerakan tari gandai

Hal ini serupa dengan yang disampaikan oleh WW (23 tahun):

“...kalau tarian gandai ko dak segalonyo samo gerakkan e, ugang cok nian ngecek puno gandai ko a, betuk tulah gerakan sampai subuh e, padahal ne dak banyak gerakan tarian nyo ugang kalau yang tau maksud gereakan tung e pasti nyo tau, betuk tari jagung, tung kan gerakan nyo mencerminkan ugang saat bercocok tanam di kebun, banyak nien jenis nyo sebena, ado go tari nenet. Cok di pakai e tari jagung tulah.

Bahasa Indonesia:

“...Tari gandai memang memiliki bentuk gerakan yang hampir sama, hanya saja jenis nya banyak, tetapi gerakan yang sering digunakan di Desa Tunggang adalah tarian gandai jagung karena menceritakan tentang keseharian masyarakat dalam aktivitas berladang sehari-hari masyarakat". 


\section{Makna Simbol Musik Pada Tarian Gandai}

Musik dalam tarian gandai berfungsi sebagai pengiring musik, tanpa adanya musik tarian gandai akan terasa kurang dan tidak akan sampai maknanya, karena alunan musik membantu penonton untuk mengetahui tarian gandai yang dipertunjukkan. Simbol yang terdapat pada musik yang digunakan tergantung alur gerakan yang digunakan, seperti simbol tari jagung, musik akan lebih mendayu seperti angin di sawah karena menceritakan warga yang sedang menanam padi.

Seperti yang dikatakan AS (23 tahun):

“...kalau musik gandai ko pasti ado untuk ngiring ugang nari, alat musik yang dipakai ko redap ngan sunai, ketika mulai musik penarik masuk ugang pasti eboh ndak nengok galo, tapi kalau dak ado musik dak bisa bejalan ugang nari tu, jadi intinyo musik ko sangat perlu.

Bahasan Indonesia:

“...Kalau musik gandai selalu ada untuk mengiringi orang menari, alat musik yang digunakan adalah redap dengan sunai, ketika mulai penarik masuk orang pasti akan berbondong-bondong data melihat pertunjukan tersebut. Tapi kalau tidak ada music tidak bisa berjalan tarian gandainya, jadi intinya musik ini sangat perlu. Berdasarkan hal tersebut musik memiliki arti penting bagi pertunjukan gandai, tanpa adanya musik gandai tidak akan berjalan karena merupakan satu kesatuan yang dilakukan secara bersamaan, jika tidak ada musik maka gandai tidak akan memiliki makna".

\section{Makna Simbol Tari Gandai Secara Etik}

\section{Makna Simbol Solidaritas}

Solidaritas merupakan kekuatan persatuan internal dari suatu kelompok. Emile Durkheim menyebut solidaritas sebagai perasaan saling percaya antar anggotanya dalam suatu kelompok dan komunitas. Berkaitan dengan masyarakat Desa Tunggang, adanya solidaritas kekeluargaan terjadi kembali erat setelah lama tak berkumpul, pada upacara perkawinan mengadakan gandai akan memunculkan simbol kebersamaan antar masyarakat dan meningkatkan solidaritas, kebersamaan ini sendiri bermakna adanya hubungan yang terjadi kembali hangat dan meningkatkan solidaritas yang sempat renggang karena kesibukan masing-masing. selain itu adanya simbol solidaritas antar sanak saudara yang hadir sambil mendengar iringan gandai sesama mereka saling bahu membahu mempersiapkan properti yang di pakai untuk upacara perkawinan keesokan harinya. Seperti yang disampaikan saudara M (50 tahun), gandai merupakan salah satu tradisi bisa merangkul kembali antara keluarga yang sebelumnya sudah jarang berkomunikasi melalui simbol dari pertunjukan gandai ini, akan secara tersirat menjelaskan sikap solidaritas yang tertanam antar keluarga maupun masyarakat yang menyaksikan pertunjukan gandai.

\section{Makna Simbol Identitas}

Identitas adalah hal penting yang harus dimiliki setiap orang karena merupakan unsur penting dalam menjelaskan jati diri seseoreang atau diri sendiri, dan status biasanya dinamakan dengan rangking atau posisi seseorang dalam lingkungan kelompoknya, atau kedudukan sebuah kelompok dalam kaitannya terhadap komunitas lain.

Berkaitan dengan masyarakat desa Tunggang sendiri terdapat simbol identitas yang erat dalam pengadaan tari gandai. Maknanya akan dikatakan masih memiliki identitas yang kental ketika masih mengadakan gandai sebagai sebuah jati diri masyarakat desa tunggang yang harus terus dilestarikan, tanpa adanya tarian gandai, tidak akan ada lagi yang mampu melihat masyarakat Tunggang dari segi ciri khasnya, atas dasar hal tersebut maka mereka terus mempertahankan adat budayanya dengan selalu mengadakan upacara pernikahan disertai gandai yang mencerminkan identitas daerah Mukomuko terkhusus Desa Tunggang yang dibuktikan dengan beragam makna simbol yang tersirat didalam pertunjukan tersebut. Agar ciri khas daerah 
mereka tetap terjaga dengan baik dan rapi sehingga menjadi sebuah jati diri yang akan terus berlanjut sampai ke generasi berikutnya.

\section{Kesimpulan}

Berdasarkan informasi-informasi di atas dapat disimpulkan tarian gandai masih selalu dilaksanakan karena memiliki makna tersendiri dalam sebuah upacara perkawinan gandai dilaksanakan dengan bertujuan mengumpulkan sanak saudara yang jarang bertemu dan berkumpul kembali gandai memiliki banyak arti penting bagi masyarakat Desa Tunggang seperti terdapat nilai-nilai moral yang mengingatkan kita harus memiliki waktu luang berkumpul dengan sanak saudara, proses sosialisasi semakin lancar, Hal-hal seperti ini disampaikan melalui proses penyampaian pantu antara penyair dan penonton yang membalas pantun dari penyair, kemudian melalui gerakan yang ditampilkan oleh anak gandai dengan berbagai jenis dari gandai akan tentunya memiliki makna simbol tersendiri mulai dari menjelaskan kehidupan masyarakat, kehidupan pengantin dan juga para masyarakat sekitar yang ikut hadir untuk menonton pertunjukan gandai tersebut, sehingga apabila gandai tidak dilaksanakan tentunya akan menghilangkan ciri khas daerah tersebut, oleh sebab itu masyarakat desa tunggang masih selalu menampilkan tarian gandai pada upacara perkawinan.

\section{Daftar Pustaka}

Endraswara, S. (2012). Metodologi Penelitian Kebudayaan. Yogyakarta: Gajah Mada University Press.

Geertz, C. (2016). Tafsir Kebudayaan. Yogyakarta: Kanisius.

Moleong, J. L. (2012). Metodelogi Penelitian Kualitatif. Bandung: PT. Remaja Rosdakarya.

Nurdiani, N. (2014). Teknik Sampling Snowball dalam Penelitian Lapangan. ComTech: Computer, Mathematics and Engineering Applications, 5(9), 1110-1118.

Refisrul, R. (2018). Eksistensi Tari Gandai Pada Masyarakat Mukomuko. Jurnal Penelitian Sejarah Dan Budaya, 4(1), 953-970.

Saiffudin, A. F. (2006). Antropologi Kontemporer. Jakarta: Kencana.

Silvia, D. (2017). Tari Gajah Menunggang. Universitas Pendidikan Indonesia.

Spradley, J. (1997). Metode Etnografi. Yogyakarta: PT. Tiara Wacana.

Yolanda, B. A., Amri, E., \& Fitriani, E. (2020). Makna Upacara Kematian Malapeh-Lapeh Bagi Masyarakat Nagari Taluak Pesisir Selatan. Culture \& Society Journal Of Antropological Research, 1(3), 193-207. 